\title{
SIMULATION OF DIFFERENT POWER TRANSMISSION SYSTEMS AND THEIR CAPACITY OF REDUCING HARMONICS
}

\author{
Ashish Dhar Diwan', Preeti Khurana ${ }^{2}$, Gaddam Siva ${ }^{3}$, Gaddam Aditya ${ }^{4}$ \\ ${ }^{I}$ M.Tech Scholar, Dept. of Electrical Engineering, Lovely Professional University, Punjab, India \\ ${ }^{2}$ Assistant Professor, Dept. of Electrical Engineering, Lovely Professional University, Punjab, India \\ ${ }^{3}$ M.Tech Scholar, Dept. of Electrical Engineering, Lovely Professional University, Punjab, India \\ ${ }^{4}$ M.Tech Scholar, Dept. of Electrical Engineering, Lovely Professional University, Punjab, India
}

\begin{abstract}
As we all know, that there are various system working all over the globe for the effective, lossless and reliable power transmission. Many different system have been tried and tested for the better stability purpose. In this paper, hybrid approach of AC-DC simultaneous transmission system has been analyzed for the better stability performance. Stability of voltage in transmission systems have been quite an issue and area of research for most of the electrical researchers. As we know, there are many different types of transmission system acting upon now a day all over the globe. Various systems have been tried and tested in different parts of the world for achieving the utmost stability of the voltage while transmission of electric power Different systems like AC system, HVDC system, AC with FACTS are in use in many places. This paper deals with different transmission systems and the level of stability achieved by those system and methods to improve the stability. Different types of transmission system have been simulated using MATLAB/SIMULINK and results have also been taken using the same.
\end{abstract}

Keywords: AC-DC, equipment, transmission, HVDC, FACTS

\section{INTRODUCTION}

As the demand is increasing rapidly with the growth of requirements of utilities in the different areas of the daily life, the power is often available at locations not close to the growing load centers but at remote locations. These locations are largely determined by regulatory policies, environmental acceptability, and the cost of available energy. The wheeling of this available energy through existing long AC lines to load centers have a certain upper limit due to stability considerations. Thus, these lines are not loaded to their thermal limit to keep sufficient margin against transient instability.[1] [4] There were many papers talking about the same concept which were read and justified. The present situation demands the review of traditional power transmission theory and practice, on the basis of new concepts that allow full utilization of existing transmission facilities without decreasing system availability and security. The flexible ac transmission system (FACTS) concepts, based on applying state-of-the-art power electronic technology to existing ac transmission system, improve stability to achieve power transmission close to its thermal limit.

The basic proof justifying the simultaneous AC-DC power transmission is explained in reference[4]. In the above references, simultaneous AC-DC power transmission was first proposed through a single circuit ac transmission line. In these proposals Mono-polar dc transmission with ground as return path was used. There were certain limitations due to use of ground as return path. Moreover, the instantaneous value of each conductor voltage with respect to ground becomes higher by the amount of the dc voltage, and more discs are to be added in each insulator string to withstand this increased voltage. However, there was no change in the conductor separation distance, as the line-to-line voltage remains unchanged. In this paper, the feasibility study of conversion of a double circuit ac line to composite ac-dc line without altering the original line conductors, tower structures, and insulator strings has been presented.

\section{TRANSMISSION SYSTEMS}

As we have talked about earlier the transmission systems are of different cadre and criteria now a day and there are many different systems have been introduced. The below description is about some of the transmission systems which are prevalent and are present with developed behavior then the earlier ones [13].

\subsection{HVAC Transmission Systems}

HVAC transmission system is being used from very early times of the electrical power. As we know that there are many different industries and domestic areas too which needs the electric power. In order to cope up with the increasing demand of the era high voltage supply became the necessity for setting up the equilibrium between demand and the supply part. But 
as we all know, HVAC transmission lines cannot be loaded to their thermal limits, it will not cope up with the supply and instability occurs in the voltage. There are certain disadvantages of this system or can be said as the problems which encounters while using the HVAC system for the transmission of electrical power they are as follows [4] :

- There is increment in current density due to increase in the loading of the line using series capacitor.

- In this system group of conductors are used which are bundled.

- In AC systems conductor carries high surface voltage gradient over it.

- There are Corona problems occurring in the system resulting in audible noise.

- Interference occurs in AC systems which effects the television screens.

- Under the conductor lines, there is a high volume of electrostatic field.

- There are switching over voltages in AC systems which causes more problems than lightning over voltages.

- In AC transmission, Ferro resonance also occurs in the system in which impedance behaves like resistance.

- Compensation done in the $\mathrm{AC}$ transmission system induces sub synchronous resonance.

\subsection{Simultaneous AC-DC Transmission}

Simultaneous AC-DC transmission system uses AC as well as DC power at a time to supply power from sending end to the receiving end. In this system each conductor of line carries AC power with the DC power super imposed over it. The DC power which is added externally do not make any clutter or interference in the power supply. This particular transmission technology uses double circuit transmission lines could be AC lines only which is modified to some level to accommodate DC power in it with the AC going along. The dual circuit AC transmission lines are used in long distance transmission for inter country as well as intra country transmission of the power for better stability then the single circuit transmission lines which are normally used for transmission purpose. In this transmission system AC and DC both run parallel in all the three phases. DC is injected into each phase of the transmission lines. As we know, the power generated at the station remain $\mathrm{AC}$ has to be converted into DC for the supply of the simultaneous power. There is a converter or a rectifier used to convert the AC supply into DC and then the DC is injected into the system. The rectifier bridge is connected to the neutral of the zig zag transformer which is at the sending end. The DC power which is injected is equally divided among all the three phases of the transmission network. This DC power is again re-converted or say inverted by the help of an inverter bridge, which is connected to the neutral of the zig zag transformer connected at the receiving end of the power system. All the transmission lines used are connected in between the zig zag transformer. This transmission technique uses double circuit transmission line in which both the power
$\mathrm{AC}$ as well as DC can be supplied at a time. Since, DC power flows into the transformer; zigzag winding connection for secondary is used to avoid the saturation of the core of the transformer.

\section{CONCEPT OF SIMULTANEOUS AC-DC POWER TRANSMISSION}

In simultaneous ac-dc power transmission system, the conductors are allowed to carry dc current superimposed on ac current. AC and DC power flow independently and the added dc power flow does not cause any transient instability [6]. The network in Fig. 1.1 shows the basic scheme for simultaneous ac-dc power flow through a double circuit ac transmission line. The dc power is obtained by converting a part of ac through line commutated 13-pulse rectifier bridge used in conventional HVDC and injected into the neutral point of the zig-zag connected secondary windings of sending end transformer. The injected current is distributed equally among the three windings of the transformer. [5] [4] The same is reconverted to $\mathrm{AC}$ by the conventional line commutated inverter at the receiving end. The inverter bridge is connected to the neutral of zig-zag connected winding of the receiving end transformer. Each transmission line is connected between the zig-zag windings at both ends. The double circuit transmission line carries both 3-phase ac as well as dc power. At both ends, zig-zag connection of secondary windings of transformer is used to avoid saturation of core due to flow of DC component current.

\section{POWER FORMULATION}

Let us assume that the rectifier's current control to be remain as constant and inverter's extinction angle control be also as constant. Under normal operating conditions the equivalent circuit can be shown as Fig.3.1. Return path of the AC current only can be shown by the dotted lines in the figure. [5]The DC power carried by each conductor of the line will be (Id / 3) along with the $\mathrm{AC}$ current per phase and the maximum values of rectifier and inverter side DC voltages can be given by $E_{\text {dro }}$ and $E_{\text {dio }}$ respectively. Line parameters in each phase of each line are $R, L$ and $C . R_{c r}$ and $R_{c i}$ are the resistances which are commutating resistances and $\alpha$ is the firing angle and $\gamma$ is the extinction angles of rectifier and inverter. The ground only carries the full DC current and all the other conductor have only 


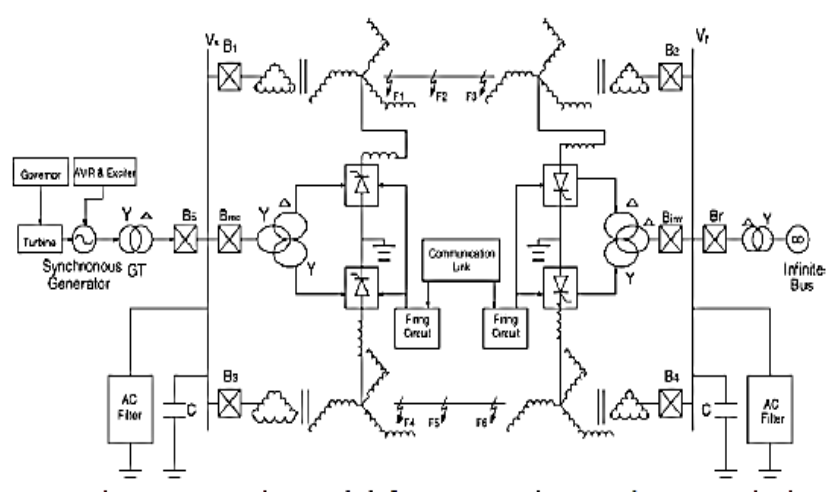

Fig 1 Simultaneous AC-DC Transmission

Id/3 along with the AC super imposed on it. The AC voltage and current and the power equations in terms of $\mathrm{A}, \mathrm{B}, \mathrm{C}$ and $\mathrm{D}$ parameters of each line can be given as, when there is resistive drop in transformer winding and in the line conductors due to DC current are neglected. The expression can be given as[5]:

Sending end voltage:

$$
\mathrm{Es}=\mathrm{AE}_{\mathrm{R}}+\mathrm{BI}_{\mathrm{R}}
$$

Sending end current:

$$
\mathrm{Is}=\mathrm{CE}_{\mathrm{R}}+\mathrm{DI}_{\mathrm{R}}
$$

Sending end power:

$$
\mathrm{P}_{\mathrm{s}}+\mathrm{jQ} \mathrm{Q}_{\mathrm{s}}=\left(-\mathrm{E}_{\mathrm{S}} \mathrm{XE_{ \textrm {R } }}\right) / \mathrm{B}+\left(\mathrm{D} \mathrm{X} \mathrm{Es}^{3} / \mathrm{B}\right)
$$

Receiving end power:

$$
P_{R}+j Q_{R}=\left(E_{S} X E_{R}\right) / B-\left(A X E_{R}^{3} / B\right)
$$

Now, the expressions for DC current and the DC power can be given as shown below, when the ac resistive drop in the line and transformer are neglected then,

Dc current:

$$
I_{d}=\left(E_{d r} \cos \alpha-E_{d i} \cos \gamma\right) /\left(R_{e r}+(R / 3)-R_{c i}\right)
$$

Power in inverter:

$$
\mathrm{P}_{\mathrm{di}}=\mathrm{E}_{\mathrm{di}} \times \mathrm{I}_{\mathrm{d}}
$$

Power in rectifier:

$$
\mathrm{P}_{\mathrm{dr}}=\mathrm{E}_{\mathrm{dr}} \times \mathrm{I}_{\mathrm{d}}
$$

Where,

$\mathrm{R} \quad=$ line resistance per conductor.
$\mathrm{R}_{\mathrm{cr}}$ and $\mathrm{R}_{\mathrm{ci}} \quad=$ commutating resistances.

$\alpha$ and $\gamma \quad=$ firing and extinction angles of rectifier and inverter respectively.

$\mathrm{V}_{\mathrm{dr}}$ and $\mathrm{V}_{\mathrm{di}} \quad=$ maximum dc voltages of rectifier and inverter side respectively.

Values of $\mathrm{E}_{\mathrm{dr}}$ and $\mathrm{E}_{\mathrm{di}}$ are 1.35 times line to line tertiary winding AC voltages of respective sides.

Reactive power required by the converters are

$$
\begin{aligned}
& \mathrm{Q}_{\mathrm{di}}=\mathrm{P}_{\mathrm{di}} \tan \theta \mathrm{I} \\
& \mathrm{Q}_{\mathrm{dr}}=\mathrm{P}_{\mathrm{dr}} \tan \theta \mathrm{r} \\
& \operatorname{Cos} \theta \mathrm{I}=(\cos \gamma+\cos (\gamma+\mu \mathrm{i})) / 3 \\
& \operatorname{Cos} \theta \mathrm{r}=(\cos \alpha+\cos (\alpha+\mu \mathrm{r})) / 3
\end{aligned}
$$

Where, $\mu \mathrm{I}$ and $\mu \mathrm{r}$ are commutation angles of inverter and rectifier respectively and total active and reactive powers at the two ends are

$$
\begin{aligned}
& \mathrm{P}_{\mathrm{st}}=\mathrm{P}_{\mathrm{s}}+\mathrm{P}_{\mathrm{dr}} \text { and } \mathrm{P}_{\mathrm{rt}}=\mathrm{P}_{\mathrm{R}}+\mathrm{P}_{\mathrm{di}} \\
& \mathrm{Q}_{\mathrm{st}}=\mathrm{Q}_{\mathrm{s}}+\mathrm{Q}_{\mathrm{dr}} \text { and } \mathrm{Q}_{\mathrm{rt}}=\mathrm{Q}_{\mathrm{R}}+\mathrm{Q}_{\mathrm{di}}
\end{aligned}
$$

Total transmission line loss is:

$$
P_{L}=\left(P_{s}+P_{d r}\right)-\left(P_{R}+P_{d i}\right)
$$

Ia being the rms AC current per conductor at any point of the line, total rms current per conductor in 3 phase becomes

$$
\mathrm{I}=\sqrt{(\operatorname{Ia} 3+(\operatorname{Id} / 3) 3)} \text { and } \mathrm{P}_{\mathrm{L}}=3 \mathrm{I}^{3} \mathrm{R}
$$

If the rated conductor current corresponds to its allowable temperature rise is $\mathrm{I}_{\mathrm{th}}$ and

$\mathrm{I}_{\mathrm{a}}=\mathrm{XX \textrm {I } _ { \mathrm { th } }} ; \mathrm{X}$ being less than one, the DC current gets to:

$$
I_{d}=3 x(\sqrt{(1-x 3)}) I_{t h}
$$

The total current I in any conductor is asymmetrical but two natural zero-crossings in each cycle in current wave are obtained for $(\mathrm{Id} / 3 \mathrm{Ia})<1.414$.

The instant value of each conductor voltage with respect to ground becomes the $\mathrm{DC}$ voltage $\mathrm{V}_{\mathrm{d}}$ with a superimposed sinusoidally varying $A C$ voltages having rms value $E_{p h}$ and the peak value being:

$$
\mathrm{E}_{\max }=\mathrm{V}+1.414 \mathrm{Eph}
$$


Electric field produced by any conductor voltage have a DC component which is superimposed with varying $\mathrm{AC}$ component[7]. Though, the electric field polarity changes its sign twice in cycle if $\left(\mathrm{V}_{\mathrm{d}} / \mathrm{E}_{\mathrm{ph}}\right)<1.414$. So, higher creep age distance requirement for insulator discs used for HVDC lines are not required in this system. Each conductor is to be insulated for maximum voltage $\left(\mathrm{E}_{\max }\right)$ but the line to line voltage has no DC component and $\operatorname{ELL}(\max )=3.45 \mathrm{E}_{\mathrm{ph}}$. Therefore, separation between two conductor distance is determined only by rated AC voltage of the line.

Let,

$$
\begin{aligned}
& \mathrm{V}_{\mathrm{d}} / \mathrm{E}_{\mathrm{ph}}=\mathrm{k} \\
& \underset{\mathrm{P}_{\mathrm{dc}} / \mathrm{P}_{\mathrm{ac}} \#\left(\mathrm{~V}_{\mathrm{d}} * \mathrm{I}_{\mathrm{d}}\right) /\left(3 * \mathrm{E}_{\mathrm{ph}} * \mathrm{Ia} * \cos \mathrm{T}\right)=(\mathrm{k}}{* \sqrt{(1-\mathrm{x} 3)) /(\mathrm{x} * \cos \mathrm{T})}}
\end{aligned}
$$

Total power can be given by

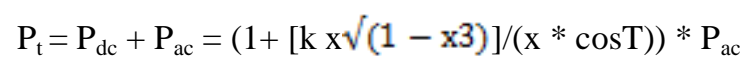

The full-fledged analysis of short current AC design of protective scheme, currently the filters used in it are not the scope of work going on right now, but the above expression says that the combine hvdc and hvac systems can be used for this purpose. In the case of any faults in the system all the SCR are gated and block the fault current from causing any damage to the system and also when the fault clears this SCRs are released after the successful; work of protecting the system. Circuit breakers are then tripped at both ends to isolate the complete system and is mentioned earlier, if $\left(\mathrm{I}_{d} 3 \mathrm{I}_{\mathrm{a}}\right)<1.414$ [5], there will be no requirement of special DC circuit breakers. The circuit breakers which are used at both the ends of transmission line will ensure to operate at zero current. The security of transmission lines can be ensured by giving proper tripping signals to the circuit breakers which is given when the current signal crosses zero which is determined by the zero crossing detector. Else, circuit breakers which are connected to the other side of transformer may be used to protect the system from faults.

\section{SIMULATION}

All the simulation and modeling process has been done by using SIMULINK package in MATLAB. We have seen and discussed about the different transmission system above and their simulation has been done here in Fig 2 is the model of hybrid AC dc transmission system. Similarly in fig 3 Simulation model of HVDC system has been given and in fig 4 Simulation model of simple AC transmission system has been provided.

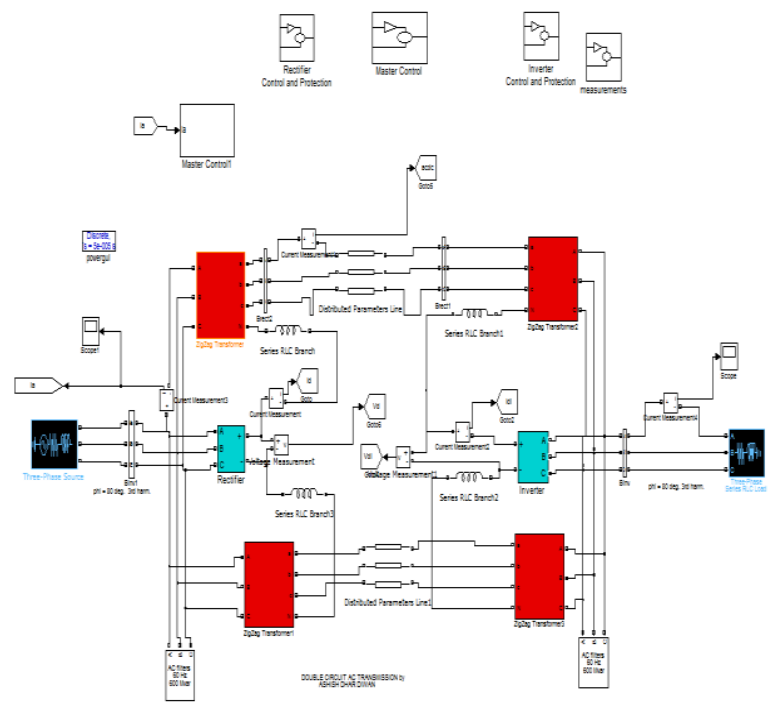

Fig 2: Simulation model of Hybrid AC-DC transmission system

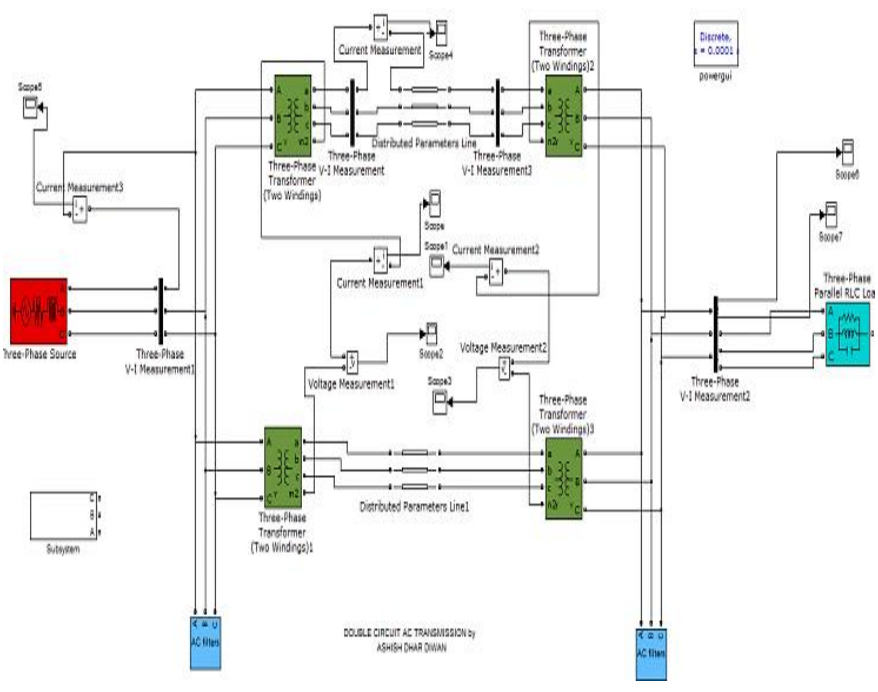

Fig 3: Simulation model of AC Transmission system

\section{RESULTS}

After the simulation of both the transmission system we have different results taken from the simulation model of $\mathrm{AC}$ system and Hybrid AC-DC system and then FFT analysis of AC, AC-DC and HVDC has been shown below. 


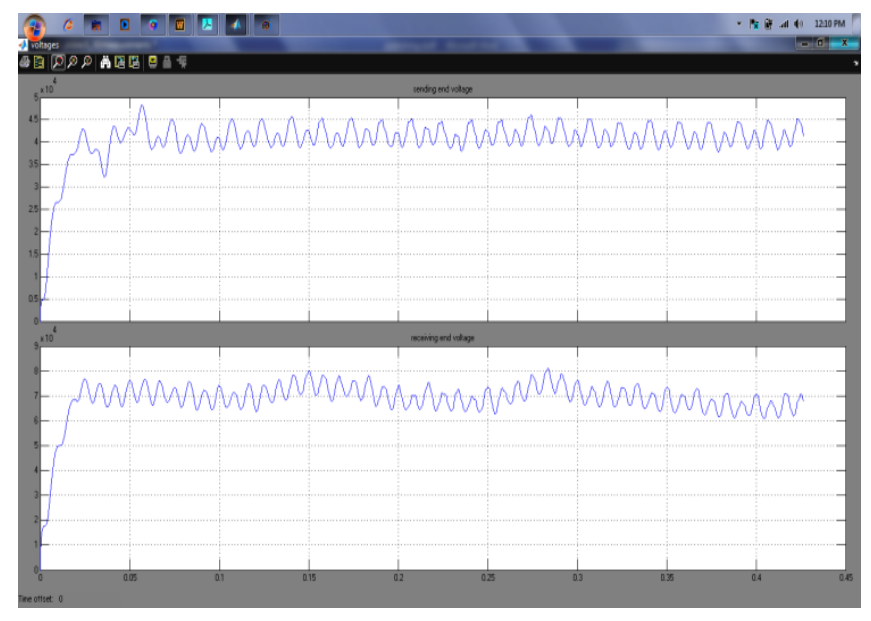

Fig 4: Sending and receiving end voltages

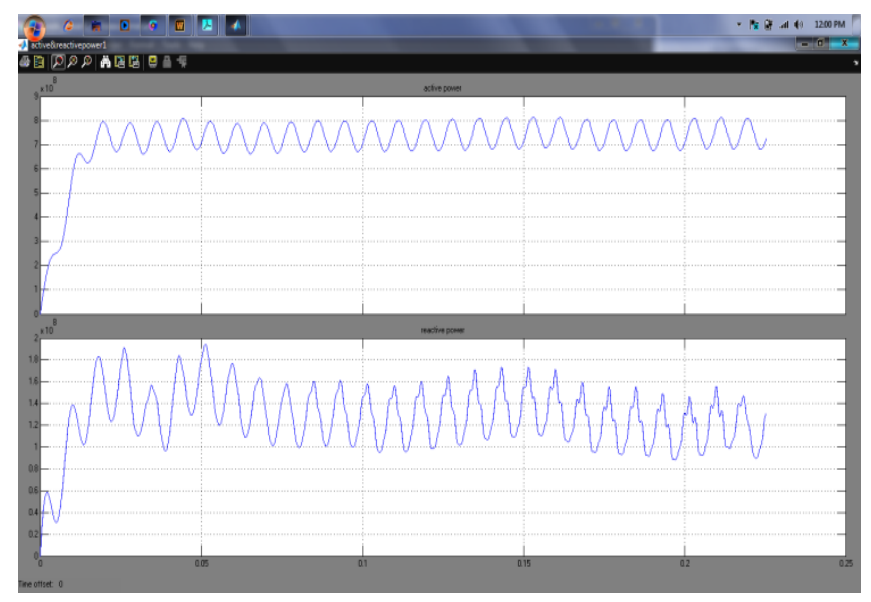

Fig 5: Sending and receiving end currents

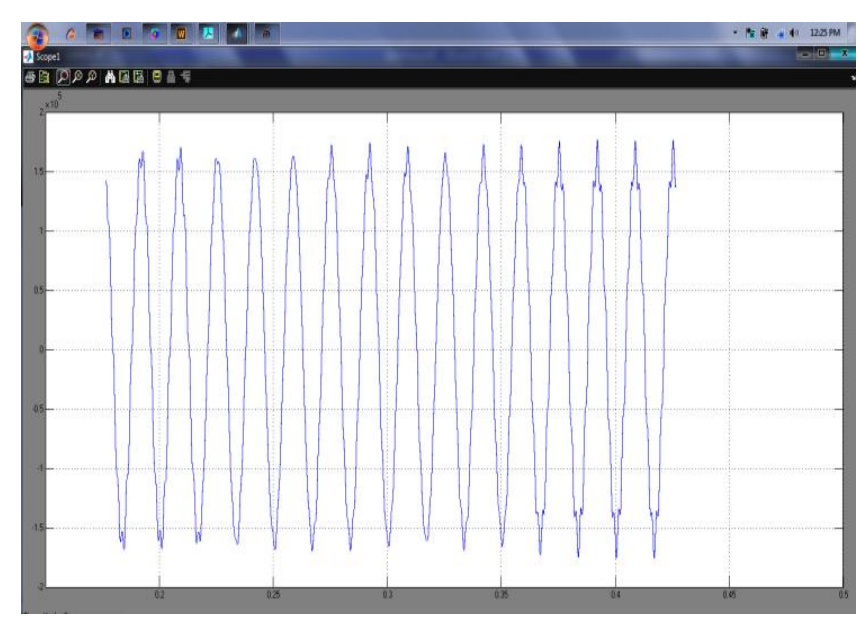

Fig 6: AC current

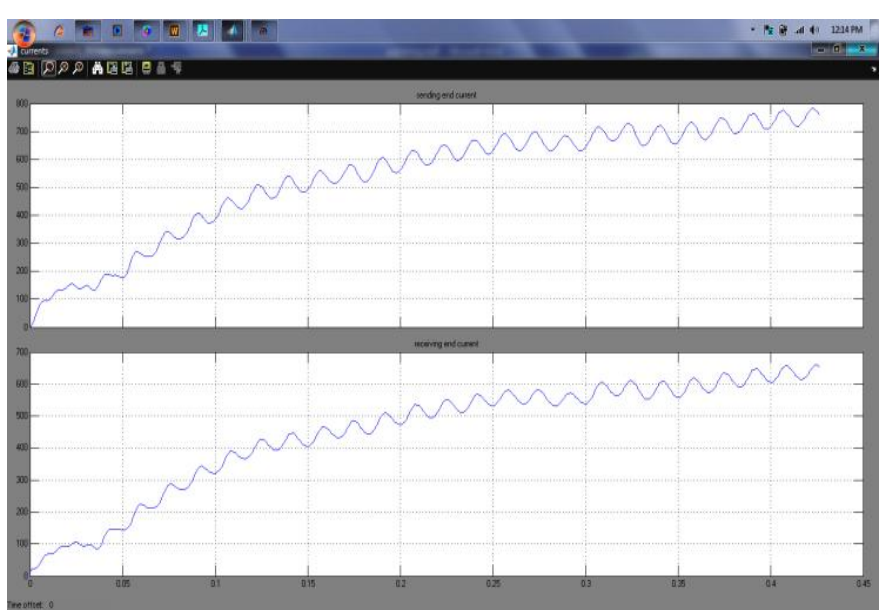

Fig 7: Sending end and Receiving end Currents

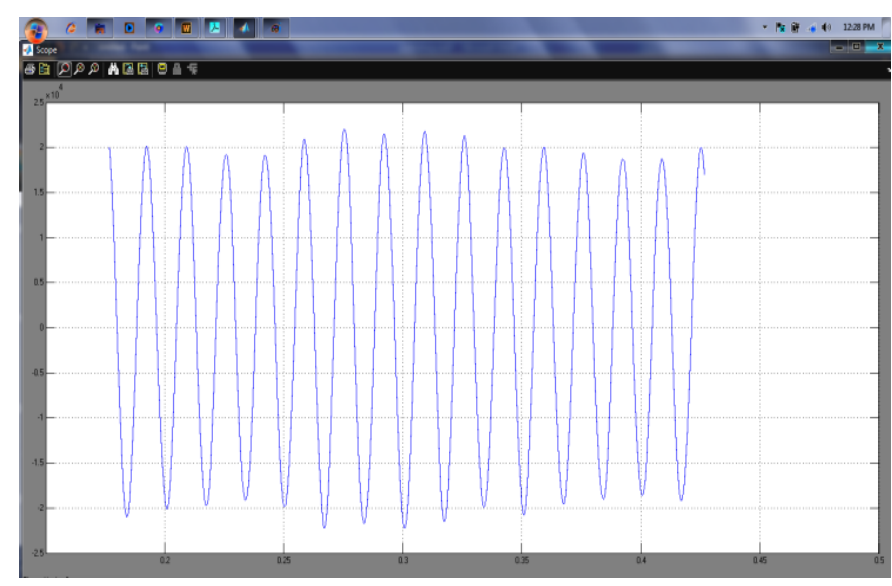

Fig 8: Combined AC-DC current

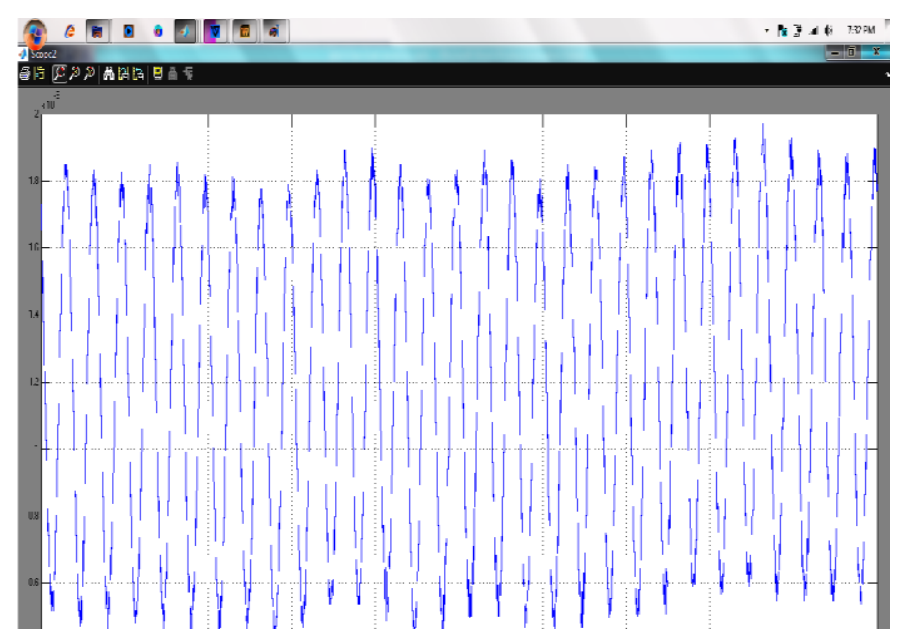

Fig 9: Transformer AC Voltage 


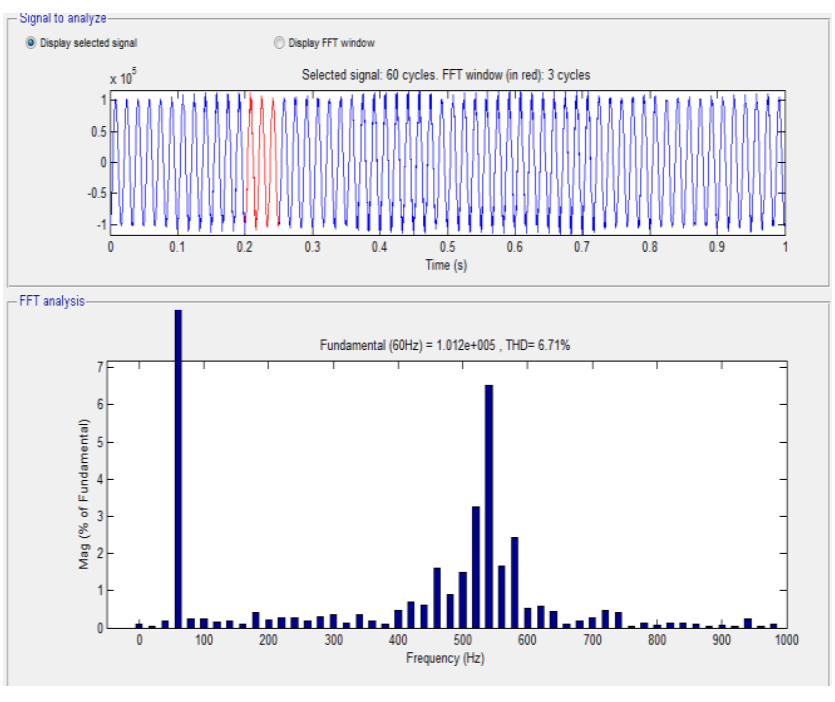

Fig 10: FFT Analysis of AC-DC system

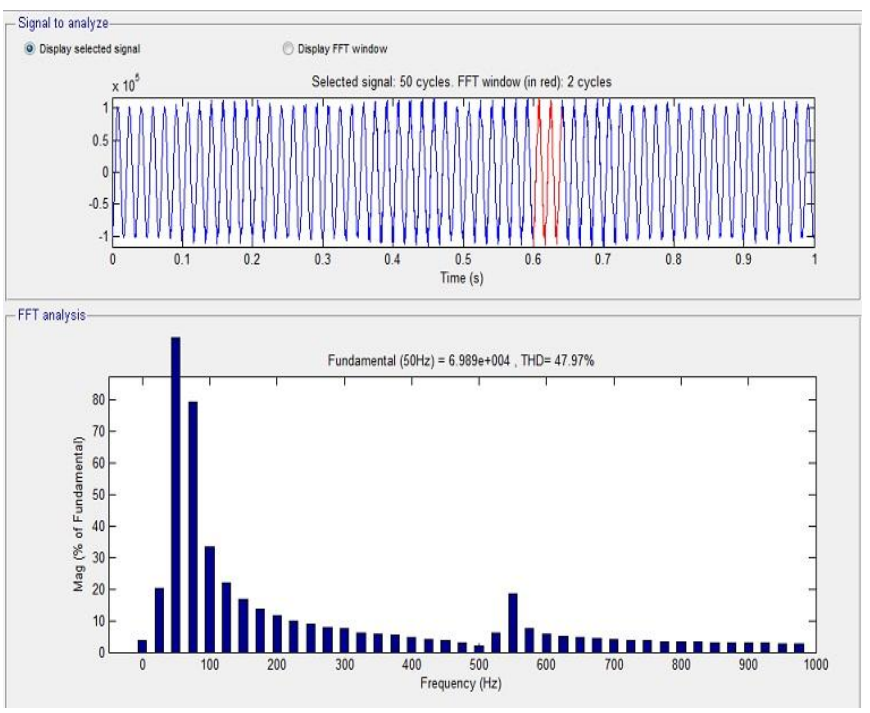

Fig 11: FFT Analysis of AC system

\section{CONCLUSIONS}

In the above discussion, we have seen the difference and the similarities between the various transmission systems and as all of them have been evaluated and the results were considered. We can observe that Hybrid AC-DC systems are showing better results than the regular AC system we use. While observing the FFT analysis it is clear that the harmonics in AC systems are more prevailed than the other two systems. There is substantial increase in the power transfer capabilities of the line and improvement in the stability in AC-DC system as compared to AC transmission systems. As new can see in the table 1 when the different values which varies as the power angle changes and there is $80 \%$ of the increase in power transfer capabilities of the line in the simultaneous AC-DC transmission system. The stability aspects up to 800 power angle have been reported in reference [12]. Now, it is better to use hybrid AD-DC transmission rather than $\mathrm{AC}$ transmission because of the benefits mentioned above in the paper. Since there is no huge amount of extra cost is required for changing the existing AC networks to AC-DC networks. No modification is required in the size of conductors, insulator strings and towers structure of the original line hybrid AC-DC is more preferable [12].

\section{REFERENCES}

[1] T.Vijay Muni, T.Vinoditha, D.Kumar Swamy (2011) "Improvement of Power System Stability by Simultaneous AC-DC Power Transmission", International Journal of Scientific \& Engineering Research Volume 2, Issue 4, April-2011.

[2] D. Povh, D. Retzmann, E. Teltsh U. Kerin, R. Mihalik , "Advantages of Large AC/DC System Interconnections", 21, rue d'Artois, F-75008 PARIS B4-304 CIGRE 2006

[3] Abhishek Chaturvedi, V. K. Tripathi, T Vijay Muni, Neeraj Singh (2013) "Power System Stability Enhancement by Simultaneous AC-DC Power Transmission", International Journal of Advanced Research in Electrical, Electronics and Instrumentation EngineeringVolume 2, Issue 5, May-2013.

[4] H. Rahman "Upgradation of Existing EHVAC Line by Composite AC-DC Transmission", international conference on communication, computer and power (ICCCP'09), MUSCAT, FEBRUARY 15-18, 2009

[5] P. Vijay Kumar Babu, P. Bhaskara Prasad, M.Padma Lalitha "Power Upgrading of Transmission Line by Combining AC-DC Transmission",International Journal of Engineering Research and Applications (IJERA) Vol. 2, Issue 6, November- December 2012, pp.1699-1704

[6] C.GOPI, M.KISHOR, “ Power Upgrading of Transmission Line by Injecting DC Power in to AC Line with the help of ZIG-ZAG Transformer",International Journal of Engineering Research and Applications (IJERA) Vol. 2, Issue 3, May-Jun 2012, pp.1042-1047

[7] Vikash Choudhary, Abdul Kadir, Prathibha Gupta, "a novel idea: simultaneous ac-dc power transmission" International Journal of Advanced Engineering Technology E-ISSN 0976-3945, IJAET/Vol. II/ Issue IV/October-December, 2011/470-474.

[8] JARUPULA SOMLAL, "Power upgrading of Transmission Line by combining AC-DC Transmission", LATEST TRENDS on SYSTEMS (Volume I).

[9] U. STRAUMANN,C.M. FRANCK, "Discussion of Converting a Double-Circuit AC Overhead Line to an AC/DC Hybrid Line with Regard to Audible Noise", CIGRE 2006. 
[10] V. Sitnikov, D. Povh, D. Retzmann,E. Teltsch, "solutions for large power system interconnections" 17- 19 Sept. 2003 St. Petersburg

[11] P. S. Kundur, Power System Stability and Control. New York: Mc- Graw-Hill,1994.

[12] H. Rahman and B H Khan "Stability Improvement of Power System by Simultaneous AC-DC Power Transmission" Electric Power System Research Journal, Elsevier, Paper Editorial ID No. EPSRD-0600732, Press Article No. EPSR-2560 - Digital ObjecTS.

[13] Ashish Dhar Diwan, Preeti Khurana "Comparative Analysis of Voltage Stability Between AC Transmission And Hybrid AC - DC Transmission Systems" IJERT, International Journal of Engineering Research \& Technology (IJERT)Vol. 3 Issue 2, February - 2014ISSN: 2278-0181 